\title{
Итоги работы АНРСК в 2018 году
}

\section{В.И. Леунов, И.М. Коноваленко}

Представлен обзор работы АНРСК в 2018 году, направленной на совершенствование современного отечественного законодательства о семеноводстве, выявление устаревших и недействительных нормативных актов, мешающих развитию отрасли, устранение необоснованных бюрократических барьеров.

Ключевые слова: семеноводство, законодательство, АНРСК.

самого своего образования в 1998 году, Ассоциация независимых российских семенных компаний (АНРСК) отстаивала и защищала интересы отрасли - селекции и семеноводства овощных, плодово-ягодных и цветочно-декоративных растений в России, целенаправленно продвигая идею создания эффективного, конкурентоспособного, цивилизованного рынка семян овощных культур. Сегодня Ассоциация - ассоциированный член ISF (Международной Федерации по семенам). Компании-члены АНРСК одновременно являются коллективными членами Российской академии естественных наук, участниками APSA (Ассоциации Семенных компаний Азиатско-Тихоокеанского региона), ASTA (Американской семеноводческой торговой ассоциации).

Накаленная мировая политическая ситуация заставляет всех граждан задумываться о будущем. Россия переживает не лучшие времена. Экономика в условиях санкций, можно сказать, перерождается заново, и это влечет неизбежность издержек, и не только в виде дефицита федерального бюджета. Члены АНРСК, например, чувствуют усиливающееся административное давление, непредсказуемость и нормативную неурегулированность в сфере отечественной селекции и семеноводства

Ассоциация сегодня объединяет более 20 организаций, которые обеспечивают производство и реализацию семян овощных, бахчевых и цветочных культур для профессионального и любительского рынков в объеме 70-90\% от их общей потребности в России. В состав АНРСК входят частные селекционно-семеноводческие фирмы (как российс- кие, так и зарубежные), а также государственные научные учреждения. При этом вектор деятельности Ассоциации направлен на решение спектра самых различных проблем связанных с ущемлением прав и законных интересов хозяйствующих субъектов. Среди них можно выделить вопросы, связанные с работой селекционных учреждений, развитием элитного семеноводства, доработки семян, реализацией конечной продукции.

Очередной этап работы Ассоциации независимых российских семенных компаний в 2018 году, пришелся на период повышенной нормотворческой активности Минсельхоза России и ФС Россельхознадзора. Эта активность была вызвана такими объективными причинами, как принятие в 2014 году Федерального закона «О карантине растений» [1], для эффективной работы которого необходимо разработать ряд подзаконных нормативных актов, обеспечивающих стабильную работу закона, однако до настоящего времени не принято и половины этих документов; а также активизацией дальнейшей работы Правительства РФ по проведению административной реформы и снижению административного давления надзор- ных органов на экономическую деятельность сельхозтоваропроизводителей России.

Совет директоров и Секретариат AНPCK, в соответствии с решениями Общего собрания AHPCK от 06.12.2017 года и заседаний Совета директоров, в отчетном 2018 году постоянно, целенаправленно и конкретно работали над превращением отечественного семеноводства в современную отрасль, развивающуюся на новейших технологиях в условиях современных рыночных отношений, для формирования в России современной законодательной базы семеноводства с.- х. растений, прежде всего овощных, цветочных, декоративных, газонных трав, цивилизованного рынка семян овощных культур в России, интеграции селекционных достижений в мировую семенную индустрию. Согласно этой стратегии была проведена следующая работа.

В отчетном году, согласно перспективного плана работы АНРCК, проведено восемь заседаний Совета директоров АНРСК, участники которых рассматривали текущие вопросы деятельности, ставили задачи на перспективу. Подготовлено и отправлено более шестидесяти писем

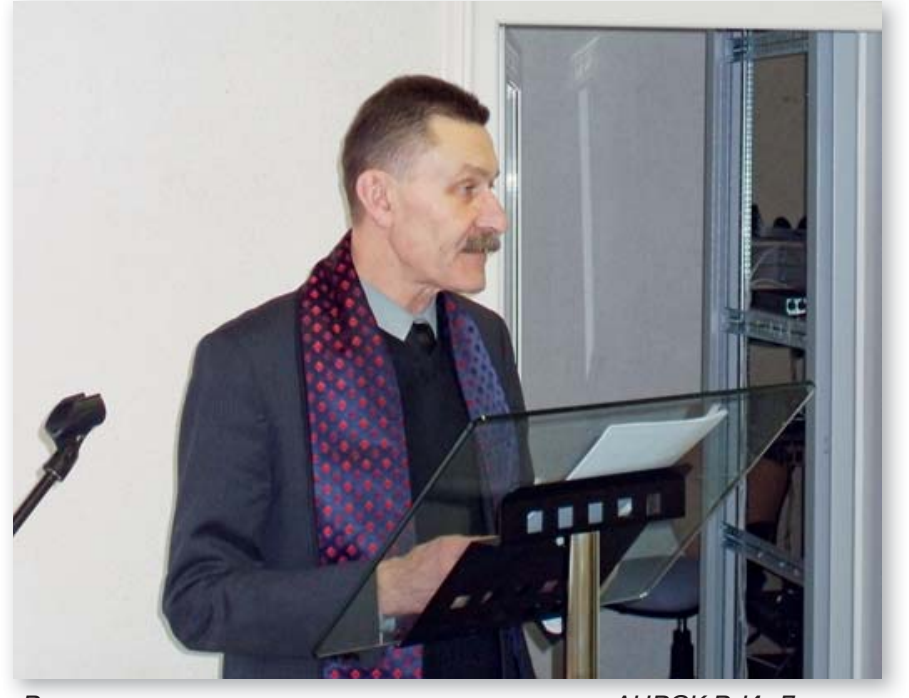

Выступает председатель совета директоров АНРСК В.И. Леунов 
в различные инстанции - МСХ РФ, Минэкономразвития, Правительство РФ, ФАС, Генеральную прокуратуру РФ, Госдуму, Совет Федерации по вопросам, касающимся урегулирования текущей деятельности компаний членов АНРСК.

AHPCK со своими проектами приняла участие в совместной работе с Общероссийской Общественной организацией малого и среднего предпринимательства «Опора России», Российского Союза Промышленников и Предпринимателей, Минэкономразвития, Т о рго в о - п р о м ы ш л е н н о й Палаты Российской Федерации и Аналитического Центра Правительства РФ.

Представитель дирекции нашей Ассоциации вошел в состав Экспертной группы сформированной в рамках исполнения приоритетной программы Правительства РФ «Реформа контрольной и надзорной деятельности», состав которой утвержден министром М.А. Абызовым [2].

Широким фронтом удалось донести позицию участников Ассоциации по проекту ФЗ «О Семеноводстве» и по проверочным листам РСН до Правительства РФ, по устаревшим приказам Минсельхоза России до Открытого правительства и Министерства юстиции РФ. Сейчас очередной проект ФЗ «О семеноводстве» проходит общественное обсуждение на портале www.regulation.ru, и мы надеемся, что он в очередной раз будет отправлен разработчику для доработки.

Несмотря на то скромное место, которое занимает наша Ассоциация в ряду организаций, принимающих участие в оценке регулирующего воздействия нормативно-правовых актов Минсельхоза России, а также несмотря на то, что Минсельхозу России иногда удается игнорировать наше существование и уклоняться от необходимых экспертных встреч некоторых побед нам все-таки удалось достичь.

С целью формирования благоприятного нормативного регулирования в сфере сельского хозяйства представители нашей ассоциации приняли участие в оценке регулирующего воздействия некоторых проектов Минсельхоза России, Правительства РФ и ФС РСН на портале Министерства экономического развития РФ - www.regulation. ru. B результате нам удалось следующее.

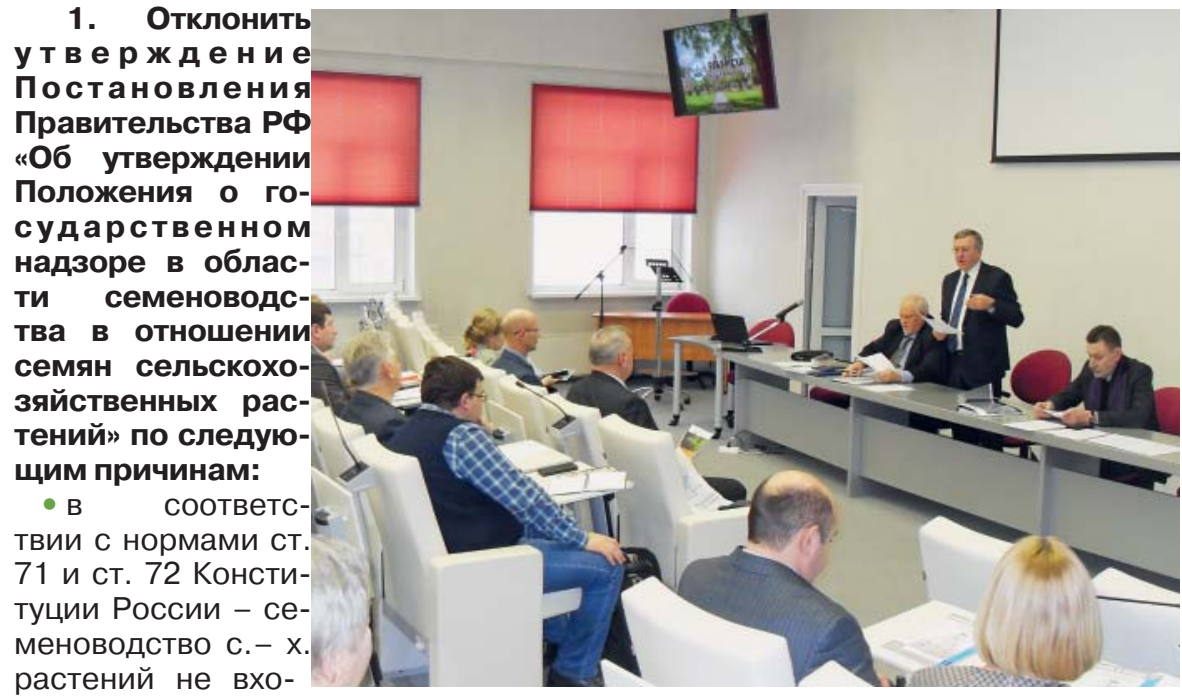

дит ни в сферу ведения РФ, ни

в сферу совмест-

ного ведения РФ и ее субъектов;

- в соответствии с нормой ст. 37.1 , 149-Ф3 «О семеноводстве» Государственный надзор в области семеноводства не является самостоятельным видом надзора и происходит только при федеральном государственном лесном надзоре (лесной охране) и государственном надзоре в области сельского хозяйства;

- проект Постановления предусматривает проведение контрольнонадзорных мероприятий в отношении семян с. - х. растений (согласно названию проекта) - что невозможно. Семена не являются субъектами права и не могут совершать противоправных действий. Нормой п. 6, ч. 5, ст. 2, 294-Ф3, установлено, что мероприятия по контролю (надзору) проводятся только в отношении юридических лиц и индивидуальных предпринимателей, но не семян;

- нормой п. 2 и п.п. «а», п. 7, проекта Постановления, установлены действия контрольно-надзорного органа в отношении нарушителей «требований» в области семеноводства семян c.- х. растений. Это противоречит п. 1, ст. 2, 294-Ф3, которым подобные действия допускаются исключительно в отношении «обязательных требований». Т.е. не любых, а только обязательных. Сегодня обязательных требований к семенам законодательством РФ не предусмотрено;

- нормой п. 10 проекта Постановления предусмотрен осмотр семян с.-х. растений, отбор образцов и проведение лабораторных исследований и экспертизы. Подобные действия незаконны, так как резуль-
Начало заседания

таты лабораторных исследований или экспертизы будут характеризовать семена по отношению к какому либо стандарту, а в соответствии со ст. 28, 149-Ф3 подтверждение соответствия семян любому стандарту осуществляется в соответствии с подобровольно;

- проект Постановления противоречит п. 2 Постановления Правительства РФ от 30 июня 2004 года №328 и п. 2 Постановления Правительства РФ от 24 марта 2006 года №164, в которых полномочия ФОИВ по организации проведения сортового и семенного контроля в отношении посевов и семян с.х. растений признаны избыточными и подлежащими упразднению.

2. Отклонить изменения, подготовленные Минсельхозом России в Постановление Правительства РФ от 31.01.2013 года № 69 «Об утверждении Положения о федеральном государственном карантинном фитосанитарном надзоре» (далее - проект Постановления), по следующим причинам:

- пункт 2 проекта Постановления, противоречит части 1, ст. 8, Ф3 «О карантине растений», так как не содержит основной задачи государственного карантинного фитосанитарного контроля, предусмотренной законом;

- подпункт «а», пункта 7 проекта Постановления устанавливает то, что тинный фитосанитарный контроль (надзор). При этом нормы, указанные разработчиком в данном пункте, противоречат части 2, ст. 8, Ф3 «О каложениями ст. 21, 184-Ф3, то есть включает государственный каран- 


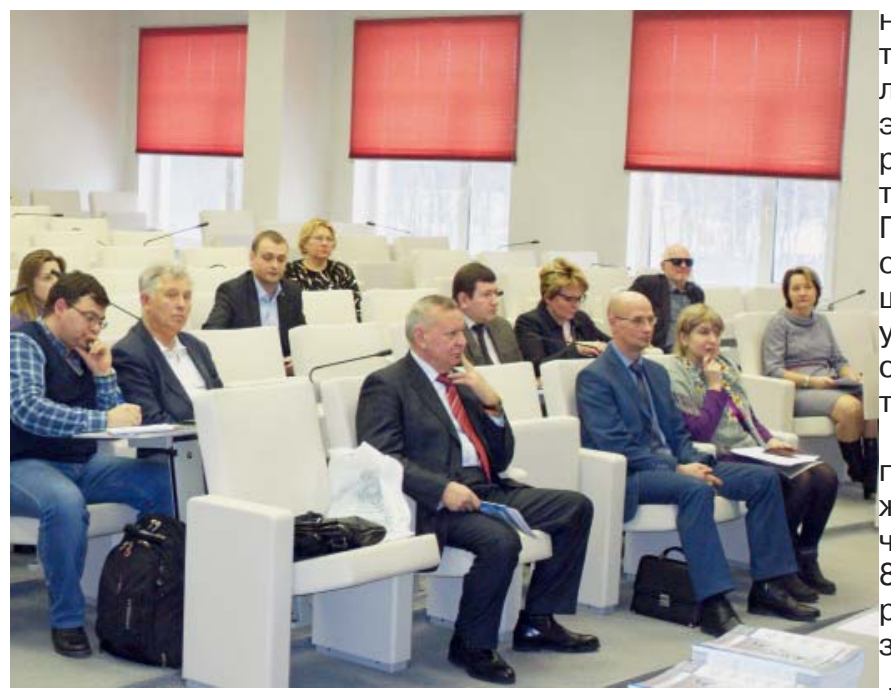

Встреча единомышленников

рантине растений», где закон однозначно устанавливает места проведения государственного карантинного фитосанитарного контроля (надзора) (ч. 1,2,3, п. 2, ст. 8), определяет предмет (ч. 4, п. 2, ст. 8) и методы контроля (п. 3, ст. 8);

- разработчик смешивает понятия государственного карантинного фитосанитарного контроля (надзора) и проверки. Между тем, ч. 7, ст. 2, Ф3 «О карантине растений», установлено, что является государственным карантинным фитосанитарным контролем (надзором), а ч. 6, ст. 2, 294Ф3 установлено, что является проверкой. Это совершенно разные мероприятия и их результаты по закону оформляются совершенно разными документами (ч. 4, п. 2, ст. 8, Ф3 «О карантине растений») и (ч. 1, ст. 16, 294-ФЗ);

- нормы подпунктов «в» и «Г», пункта 7 проекта не являются предметом государственного карантинного фитосанитарного контроля (надзора), поэтому не могут содержаться в данном проекте Постановления Правительства;

- пункты 8 и 16 Положения, устанавливают виды проверок. При этом таких полномочий разработчику закон не дает. Ст. 7, ФЗ «О карантине растений» поручается установить Порядок проведения Государственного карантинного фитосанитарного контроля (надзора). Порядок проведения проверок и их виды устанавливаются другим законом - № 294-Ф3;

- пункт 9 проекта Положения устанавливает мероприятия, которые будут проводиться при осуществлении Государственного карантин- ного фитосанитарного контроля (надзора). При этом перечень мероприятий проекта Постановления Правительства необоснованно расширяет перечень установленный ч. 3 ст. 8, Ф3 «О карантине растений»; - пункт 13 проекта Положения противоречит п. 2 и п. 3, ст. 8, Ф3 «О карантине растений», так как законом установлено, что государственный карантинный фитосанитарный контроль (надзор) осуществляется не за деятельностью, а за выполнением работ, и не везде, а в строго установленных местах;

- пунктом 17 и 18 Положения вводится некий «Перечень объектов контроля». Таких поручений в ст. 7, Ф3 «О карантине растений» не содержится;

- приложением к проекту Положения установлены объекты государственного контроля. Данный перечень разработчиком чрезмерно расширен и выходит за пределы установленного ст. 8, Ф3 «О карантине растений»;

- подпунктом «а», пункта 3.1.1 приложения к проекту Положения предусмотрено отнесение к категориям риска в зависимости от нарушения «Правил борьбы с карантинными, особо опасными и опасными вредителями растений, возбудителями болезней растений, растениями-сорняками». Ответственность за данные нарушения предусмотрена ст. 10.1 КоАП РФ. Ответственность нормами КоАП действительно предусмотрена, но самих Правил борьбы с карантинными, Правил борьбы с особо опасными и опасными вредителями растений, Правил борьбы с возбудителями болезней растений, Правил борьбы с растениями-сорняками не существует, следовательно, нарушить их невозможно, а надзорный орган сможет манипулировать составами правонарушений;

- подпункт «в», пункта 3.1.1 приложения к проекту Положения не является предметом Государственного карантинного фитосанитарного контроля (надзора).
3. В рамках работы Экспертной Рабочей Группы № 5, состав которой утвержден министром M.A. Абызовым по программе «Реформа контрольной и надзорной деятельности».

Был проведен анализ регулирующего воздействия Приказа Минсельхоза России от 13 июля 2016 года № 293 «Об утверждении порядка выдачи фитосанитарного сертификата, реэкспортного фитосанитарного сертификата, карантинного сертификата» (зарегистрирован в Минюсте России 12 августа 2016 г.). Приказ ограничивал право участников Ассоциации на оформления карантинного сертификата без проведения обеззараживания склада получателя продукции, также это право ограничивалось необходимостью отсутствия правонарушений в области карантина растений. А одну и ту же партию подкарантинной продукции приходилось платно обследовать каждый раз при оформлении фитосанитарных документов.

В результате 13 февраля 2018 года, Приказом Министра сельского хозяйства РФ № 64, Приказ Минсельхоза от 13.07.2016 № 293 был изменен. В частности:

- устранен барьер, когда карантинный сертификат (далее - КС) оформлялся на каждую партию подкарантинной продукции вывозимую из карантинной зоны. Теперь КС оформляется только на ту подкарантинную продукции, для которой характере карантинный объект, в связи с выявлением которого установлена зона;

- больше не требуется документ, подтверждающий проведение профилактического фитосанитарного обеззараживания складских помещений, предназначенных для хранения заявленной к ввозу подкарантинной продукции;

- больше не требуется проводить лабораторное обследование части партии для оформления фитосанитарных документов. Заключение теперь оформляется на всю партию и действует до тех пор, пока партия не переместится в новое место хранения;

- больше не требуется отсутствие неустраненных нарушений в области карантина растений, касающихся заявленной продукции, мест ее заготовки, хранения и переработки, а также способов ее транспортировки;

- теперь переоформить фитосанитарный сертификат можно даже тогда, когда срок его действия истек;

- отменен Приказ Минсельхоза 
России 414, который устанавливал необходимость проведения ежегодных, профилактических карантинных фитосанитарных обеззараживаний. Сегодня такой необходимости законом больше не предусматривается.

4. Также был проведен анализ регулирующего воздействия Приказа Минсельхоза России от 13 февраля 2008 года № 43 «Об установлении и упразднении карантинной фитосанитарной зоны, установлении и отмене карантинного фитосанитарного режима, о наложении и снятии карантина» (зарегистрирован в Минюсте России 5 марта 2008 года № 11281) [3]. Этот приказ, как дамоклов меч, висел над каждым предприятием, осуществляющим свою деятельность в сфере сельского хозяйства.

В результате, аналитический материал был направлен в Министерство Экономического Развития и Министерство Юстиции России, с предложением предписать Минсельхозу России, отменить Приказ № 43, противоречащий действующему законодательству и препятствующие нормальному развитию бизнеса.

Сегодня проект приказа Минсельхоза России об отмене Приказа 43 подготовлен и размещен на портале regulation для общественного обсуждения. Таким образом, после отмены данного приказа заработают нормы 206-Ф3 «О карантине растений» о порядке установления и отмены карантинных фитосанитарных $30 \mathrm{H}$.

5. Чтобы решить проблему ежегодного оформления в Минсельхозе России «выписок из Реестра селекционных достижений, допущенных к использованию». Был проведен анализ регулирующего воздействия Приказа Минсельхозпрода России от 1 июля 1997 года № 306 «О порядке ввоза на территорию Российской Федерации и вывоза с территории Российской Федерации семян сортов растений и племенного материала пород животных», устанавливающий порядок оформления этих документов.

Установлено, что данный Приказ отменен Приказом Минсельхоза России еще 23 ноября 2001 года № 1054 «Об отмене Приказа Минсельхозпрода России от 1 июля 1997 г. № 306 «О порядке ввоза на территорию Российской Федерации и вывоза с территории Российской Федерации семян сортов растений и племенного материала пород животных» [4].
Между тем, выписки из Реестра продолжают оформляться и сегодня, чем серьезно осложняют деятельность лиц ввозящих на территорию РФ семена и посадочный материал. Поэтому было рекомендовано обратиться в Министерство Экономического Развития и Министерство Юстиции России с предложением предписать Минсельхозу России, исполнить Приказ Минсельхоза № 1054 и отменить «Инструкцию о ввозе» утвержденную Минсельхозпродом и ФТС России 08.05.1997 года, на основании которой такие выписки в настоящее время применяются при таможенном оформлении семян и посадочного материала.

Сегодня «Инструкция о ввозе» не отменена, работа по ее отмене продолжается и к ней предполагается привлечь ФТС России.

6. Чтобы решить проблему с проведением систематических карантинных фитосанитарных обследований, проверок, замаскированных под карантинные фитосанитарные обследования, назначения лиц ответственных за карантин и ведения журналов учета - проведен анализ приказа Минсельхоза России № 160.

В результате, аналитический материал был направлен в Министерство Экономического Развития и Министерство Юстиции России, с предложением предписать Минсельхозу России, отменить Приказ № 160, как противоречащий действующему законодательству и препятствующие нормальному развитию бизнеса.

23 августа 2018 года Министром сельского хозяйства РФ Д.Н. Патрушевым подписан, а 17 сентября 2018 года зарегистрирован (№ 52170) в Министерстве Юстиции РФ Приказ МСХ РФ № 385 «О признании утратившими силу приказов Министерства с/х РФ от 22.04.2009 № 160 и от 26.03.2013 № 148» [5].

Таким образом, сегодня больше не существует обязанности проводить систематические карантинные фитосанитарные обследования своих предприятий. Больше не требуется распорядительного документа о назначении ответственного за такие обследования, а также плана проведения систематических обследований. Законом установлен только один вид обследования - карантинное фитосанитарное (п. 21, ст. 2, 206-Ф3 «О карантине растений»). При этом законом установлено, что карантинное фи- тосанитарное обследование проводит только должностное лицо Россельхознадзора.

7. Чтобы решить проблему участников Ассоциации с необходимостью исполнения нормативных актов СССР и нормативных актов, содержащих необязательные нормы, был проанализирован Приказ ФС Россельхознадзор № 744 «Об утверждении Перечня правовых актов и их отдельных частей (положений), содержащих обязательные требования, соблюдение которых оценивается при проведении Россельхознадзором мероприятий по государственному контролю (надзору) и Порядка его ведения» (далее - Приказ 744).

Приказ 744 представляет собой перечень нормативных актов, содержащих обязательные требования, которые могут проверяться при проведении проверок. Проявив чрезмерную свободу подзаконного нормотворчества, ФС Россельхознадзор необоснованно включила в данный приказ НПА СССР и НПА с необязательными нормами, что препятствовало свободному предпринимательству и осложняло проведение проверок незаконными требованиями

Поскольку такие действия противоречили норме п. 1.1, ст. 15, Ф3 от 26.12.2008294-Ф3 «О защите прав юридических лиц и индивидуальных предпринимателей при осуществлении государственного контроля (надзора) и муниципального контроля», которой прямо запрещено «... проверять выполнение требований, установленных нормативными правовыми актами органов исполнительной власти СССР и РСФСР», мы предложили направить Представление Рабочей Группы № 5 на имя Руководителя РСH России с предложением внести изменения в свой приказ.

Сегодня изменения внесены, но пока не все замечания Ассоциации учтены. Поэтому работа в этом направлении продолжается.

8. В сентябре 2018 года Минсельхоз России разместил на портале www.regulation.ru проект Федерального Закона «О семеноводстве». Этот Законопроект должен был привести нормы закона в соответствии с Конституцией Российской Федерации, Гражданским кодексом, Федеральным законом от 27.12.2002 № 184 - Ф3 «О техническом регулировании» и иными федеральными законами. 
Этот проект также был проанализирован и установлено что разработчики предлагают:

- вернуть незаконную обязательную сертификацию семян;

- узаконить незаконное ведение государственного реестра селекционных достижений, допущенных к использованию;

- создать предмет для проведения проверок Россельхознадзором;

- вмешиваться в процесс селекции;

- создать федеральную информационную систему в области семеноводства, противоречащую закону о коммерческой тайне таким образом, чтобы публиковать информацию об объемах и месте производства семян отечественных селекционных фирм, чтобы иностранные селекционеры смогли получить данные о родительских формах, используемых при производстве гибридных семян - т.е., опубликовать ноу-хау российских селекционеров;

- узаконить обязательный платный ГМО-контроль за семенами (сегодня он проводится за счет бюджета).

Таким образом, этот законопроект способен отрицательно повлиять на рынок семян в России. Требуется серьезная работа над законопроектом с привлечением самого широкого экспертного сообщества. Пора повернутся лицом к отечественному сельхозпроизводителю, и рассматривать его как источник налоговых поступлений в казну государства, а не источник иных доходов для различных государственных структур. Аналитические замечания и факты противоречия закону направлены в Министерство Экономического развития РФ.

В то же время остается еще очень много проблем, и мы считаем необходимым продолжение активной работы в сфере законодательно-нормативной регламентации семеноводства, организационной структуры отрасли. Разработки предложений по созданию условий привлечения в Ассоциацию других участников рынка семян, обеспечению развития сотрудничества с международными организациями - ISF, ИCTA, UPOV, OECD, семеноводческими ассоциациями развитых стран с целью дальнейшей унификации национального законодательства семеноводства, формирования взаимовыгодных экономических и научных связей. В составе нашей Ассоциации представлены далеко не все участники рынка семян, еще многие компании, ассоциации и союзы страны, индивиду- альные селекционеры, не входят в ее состав, но это не значит, что деятельность Ассоциации сконцентрирована на проблемах только своих членов. Сегодня мы по существу представляем интересы всего сообщества семеноводов. У каждого из них возникают такие же проблемы и многочисленные вопросы, и мы уверены, что только совместными усилиями мы можем сделать сферу селекции и семеноводства благоприятной для успешной деятельности.

В январе 2019 года в стенах РГАУ-МСХА имени К.А. Тимирязева состоялось очередное заседание AНРСК, посвященное итогам работы Ассоциации в 2019 году. Среди участников мероприятия были представители частного бизнеса (агрохолдинг «Поиск», компания «Гавриш», агрофирма «Аэлита» и др.), государственных структур (Минсельхоз, ФАС, Россельхознадзор, ФГБУ «Россельхозцентр» и др.), ФГБОУ ВО РГАУ-МСХА имени К.А. Тимирязева, Картофельного союза, ассоциации «Теплицы России», Евразийского Экономического Союза. Все они были едины во мнении, что необходимо и далее устранять необоснованные преграды на пути развития российского семеноводства, выявлять устаревшие нормативно-правовые акты, разрабатывать актуальные предложения.

В следующем рабочем периоде Ассоциации предстоит сконцентрировать усилия по решению вопросов связанных с созданием новых современных условий для развития селекции и семеноводства овощных культур, и прежде всего, по государственному субсидированию селекционных программ в овощеводстве, независимо от форм собственности селекционных организаций, расширению научных исследований по разработке новых селекционных методик; параметров технологических приемов, оптимизации налоговой политики в селекции и семеноводстве, льготного кредитования в этой сфере, обеспечить дальнейшее совершенствование нормативно-правовой базы селекции и семеноводства с обеспечением современных требований рыночной экономики, устранения административных барьеров и ряду других вопросов.

Мы готовы к сотрудничеству со всеми государственными организациями. У нас есть понимание необходимых действий для развития семеноводства и для восстановления производства семян в нашей стране. Мы более других заинтересованы в возможности выращивать для себя качественные семена именно в России. Мы обращаемся к представителям различных органов государственной власти с призывом: увидьте в нас достойных партнеров, вместе с которыми вы сможете разрабатывать и принимать правильные, актуальные, необходимые нормативные акты, а также успешно работать в дальнейшем.

\section{Библиографический список}

1.Федеральный закон “О карантине растений» от 21.07.2014 N 206-Ф3 (последняя редакция) [Электронный ресурc]. URL: http://www.consultant.ru/ document/cons_doc_LAW_165795/. Дата обращения: 29.01.2019.

2.Приоритетная программа «Реформа контрольной и надзорной деятельности» («Реформа КНД») [Электронный ресурc]. URL: http://government.ru/ projects/selection/655/. Дата обращения: 29.01.2019.

З.Об установлении и упразднении карантинной фитосанитарной зоны, установлении и отмене карантинного фитосанитарного режима, о наложении и снятии карантина [Электронный ресурc]. URL: http://docs.cntd. ru/document/902090649. Дата обращения: 29.01.2019. 4.Об отмене Приказа Минсельхозпрода России от 1 июля 1997 г. N 306 «О порядке ввоза на территорию Российской Федерации и вывоза с территории Российской Федерации семян сортов растений и племенного материала пород животных» [Электронный pecypc]. URL: http://docs.pravo.ru/document/ view/33615/37625/. Дата обращения: 29.01.2019.

5.Отмена Приказа Минсельхоза России № 160 «Об утверждении Правил проведения карантинных фитосанитарных обследований» [Электронный ресурс]. URL: http://www.newpotatoes.ru/novosti/? ELEMENT_ID=31. Дата обращения: 29.01.2019.

\section{Об авторе}

Леунов Владимир Иванович, доктор с. - х. наук, профессор, председатель совета директоров АНРСК, и. о. декана факультета агрономии и биотехнологии РГАУ-МСХА имени К.А. Тимирязева. E-mail: vileunov@mail.ru Коноваленко Иван Михайлович, исполнительный директор АНРCК. E-mail: info@anrsk.ru

Totals of work of AIRSC in 2018 V.I. Leunov, DSc, prof., the chairman of board of directors of AIRSC, acting dean of department of agronomy and biotechnology, Russian State Agrarian University - Moscow Timiryazev Agricultural Academy named after K.A. Timiryazev. E-mail:leunov@mail.ru

I.M. Konovalenko, executive director of ANRSC. E-mail: info@anrsk.ru

Summary. An overview of the work of AIRSC in 2018, aimed at improving the current national legislation on seed production, identifying outdated and ineffective regulations that hinder the development of the industry, the removal of unnecessary bureaucratic barriers, is presented.

Keywords: seed production, legislation, AIRSC. 